\title{
Expression of CD133 and Extracellular Matrix Molecules in Malignant Brain Tumors
}

\author{
Seiichi Yoshida*, Toshiro Koike \\ Department of Neurosurgery, Tsubame Rosai Hospital, Tsubame-City, Japan. \\ E-mail: ${ }^{*}$ sei22@tsrh.jp \\ Received October $5^{\text {th }}, 2011$; revised November $12^{\text {th }}, 2011$; accepted November $25^{\text {th }}, 2011$.
}

\begin{abstract}
Background: CD133 could be characterized as a "stem-like" cell subpopulation and an invasive tumor phenotype. The objectives of this study were to investigate the relationship of $C D 133$ and other remodeling factors such as matrix metalloproteinases (MMP) in the brain tumors. Methods: Tumors from 13 patients with brain tumors (8 lung cancer metastasis, 3 breast cancer metastasis, 2 gliomas) were studied to investigate the expression-patterns of CD133, EGFR, MT1-MMP, and MMP7 using the immunostaining and RT-PCR analysis. Results: EGFR immunostaining was detected in $75 \%(6 / 8)$ and $67 \%(1 / 3)$ of brain metastasis from lung adenocarcinoma and breast cancer, respectively. MT1-MMP immunostaining was also detected in $73 \%(8 / 11)$ of these brain metastasis. CD133 was not detected in these 13 patients. EGFR immunostaining was detected in $75 \%(6 / 8)$ and $67 \%(1 / 3)$ of brain metastasis from lung adenocarcinoma and breast cancer, respectively. MT1-MMP immunostaining was also detected in 73\% (8/11) of these brain metastasis. CD133 was not detected in these 13 patients. Conclusions: The expression of CD133 indicates a marker for brain tumor initiating.
\end{abstract}

Keywords: CD133, EGFR, MT1-MMP, MMP7, Brain Tumors

\section{Introduction}

A small population of cancer stem cells (CSCs) within neoplasm is supposed to be responsible for long-term tumor proliferation [1]. Some groups have also subsequently showed that CSCs exist in brain tumor, [2], and CD133 could be characterized as a marker of CSCs subpopulation and an invasive tumor phenotype $[3,4]$.

The malignant brain tumors contain CSCs are also thought to show higher NOTCH activity [5]. The NOTCH pathway may be also related to many remodeling factors such as matrix metalloproteinases (MMP) in the brain tumors. It is reported that the NOTCH pathway represents a possible target in stem-like malignant brain tumor cells [6]. Furthermore, it has recently been reported that common chemotherapeutic drugs, as well as traditional radiation therapy, predominantly targeted the CD133negative population $[7,8]$. The NOTCH pathway represents a possible target in stem-like malignant brain tumor cells $[9,10]$. In this study, we investigate the relationship of CD133 and other remodeling factors such as MMPs concerning with the NOTCH pathway in the malignant brain tumors $[11,12]$.

\section{Patients and Methods}

Tumors from 15 patients with malinant brain tumors (Table 1) were studied to investigate the expressionpatterns of CD133, EGFR, MT1-MMP, MMP7, and CD44 using the immunostaining and RT-PCR analysis.

\section{Immunostaining}

All these drugs are reported to be unable to penetrate the blood-brain-barrier. Sections of paraffin-embedded tissues were studied by the immunohistochemistry(IHC) using monoclonal antibodies to CD133, EGFR, MT1MMP, MMP7, and CD44 (Oncogene Research Labs). Using the methods described previously [13], 8-micro $\mathrm{mm}$ sections were treated using the avidin-biotin-peroxidase complex method (Vectastatin Elite ABC kit; Vector Labs). Endogenous peroxidase activity was blocked with $3 \% \mathrm{H}_{2} \mathrm{O}_{2}$ in methanol for $30 \mathrm{~min}$. Sections were blocked with $20 \%$ horse serum for $1 \mathrm{~h}$. Primary antibody at 1:100 dilution was applied overnight at $40^{\circ} \mathrm{C}$. Secondary biotinylated antibody at 1:200 dilution was applied for $1 \mathrm{~h}$ to visualize the bound antibody. $\mathrm{ABC}$ reaction was performed for $1 \mathrm{~h}$ at room temperature. The peroxi- 
Table 1. Characteristics of patients.

\begin{tabular}{cccc}
\hline Tumor type & $\begin{array}{c}\text { Age (yr) Average TTD } \\
\text { from Met }{ }^{b}(\mathrm{mo})\end{array}$ & \multicolumn{2}{c}{ Previous chemotherapy } \\
\cline { 3 - 4 } & & No & Yes \\
\hline $\begin{array}{c}\text { Malignant glioma } \\
(\mathrm{n}=2)\end{array}$ & $48-68$ & 2 & 0 \\
$\begin{array}{c}\text { Lung carcinoma } \\
\text { adeno (n=8) }\end{array}$ & $47-73$ & 9.3 & 35 \\
$\quad \begin{array}{c}\text { squamous } \\
(\mathrm{n}=2)\end{array}$ & $65-77$ & 7.6 & 11 \\
$\begin{array}{c}\text { Breast carcinoma } \\
(\mathrm{n}=3)\end{array}$ & $38-62$ & 14.2 & 30 \\
\hline
\end{tabular}

${ }^{\mathrm{a}} \mathrm{TTD}$, time to death; ${ }^{\mathrm{b}}$ Metbrain metastasis; ${ }^{\mathrm{c}}$ chemotherapy, seven of the 15 patients had been treated for the primary lesions with anticancer drugs.

dase activity was developed by incubation in $0.05 \%$ 3,3-diaminobenzidine for $3 \mathrm{~min}$. Control sections were obtained from the surrounding brain tissues where no cancer cells were detected.

\section{Reverse Transcription/Polymerase Reaction (RT-PCR)}

The obtained brain tumor tissues were frozen in liquid nitrogen and stored at $-80^{\circ} \mathrm{C}$. Total RNA was prepared using the RNase Mini Kit according to the manufacture directions(Qiagen, Chatsworth, CA). The RNA samples were reverse-transcribed using Superscript reverse transcriptase (Life Technologies Inc., Gaithersburg, MD.), random hexamers, and dNTPs. cDNA synthesized were amplified by PCR( 30 cycles) with Taq DNA polymerase (Qiagen, Chatsworth, CA) in the presence of both dNTP and an appropriate pair of primers. The following sense and anti sense primer was used:

CD133 forward primer 5'-CAG AGT ACA ACG CCA AAC CA-3',

CD133 reverse primer 5'-AAA TCA CGA TGA GGG TCA GC-3'.

EGFR sense; 5-AGCGGATAACAATTTCACACAGG-3 anti-sense; 5-GTCGTCTTTCCAGACGTTAGT-3

MT1-MMP sense; 5-ACAGTCTGCGGAACGGAGC AG-3

anti-sense; 5-GTCAATTGTGTTTCTGTCCAC-3 MMP7 sense; 5-GTGGTCACCTACAGGATCGTA-3 anti-sense; 5-CTGAAGTTTCTATTTCTTTTTGA-3 CD44 sense; 5-GTACGTCTTCAAATACCA-3 anti-sense; 5-GTGGTTGAAATGGTGC-3

$\beta$-actin forward primer 5'-GTC TTC CCC TCC ATC GTG-3',

$\beta$-actin reverse primer 5'-AGG TGT GGT GCC AGA TTT TC-3',

Results were expressed as band intensity in each lane relative to GAPDH and compared statistically using
Student's t test.

\section{Statistical Analysis}

The immunohistochemical and PCR activities measured in this study were analyses using the Student t-test. A probability value less than 0.05 was considered statistically significant.

\section{Results}

\subsection{Immunohistochemistry}

EGFR immunostaining was detected in $75 \%(6 / 8)$ and $67 \%(1 / 3)$ of brain metastasis from lung adenocarcinoma and breast cancer, respectively. MT1-MMP immunostaining was also detected in $73 \%(8 / 11)$ of these brain metastasis. CD133 was not detected in these 13 patients. EGFR immunostaining was detected in $75 \%(6 / 8)$ and $67 \%(1 / 3)$ of brain metastasis from lung adenocarcinoma and breast cancer, respectively (Figure 1). MT1-MMP immunostaining was also detected in $73 \%(8 / 11)$ of these brain metastasis. CD133 was not detected in these 13 patients (Table 2).

\subsection{Identification of Gene Expression}

Figure 2 shows the relative gene expression levels of brain metastasis from lung cancer for EGFR, MT1-MMP, MMP7, and CD44. Table 3 summarizes the RT-PCR results. EGFR mRNA was detected in 83.3\% (25/30) and $70 \%(7 / 10)$ of brain metastasis from lung cancer and breast cancer, respectively. MT1-MMP mRNA was detected in $73.3 \%(22 / 30)$ specimens of brain metastasis from lung cancer, and only $13.3 \%$ (4/30) specimens of these patients expressed MMP7 mRNA. MT1-MMP mRNA was also detected in 50\% (5/10) of brain metastasis from breast cancer. As for the correlation between EGFR and other gene expression, gene expression of

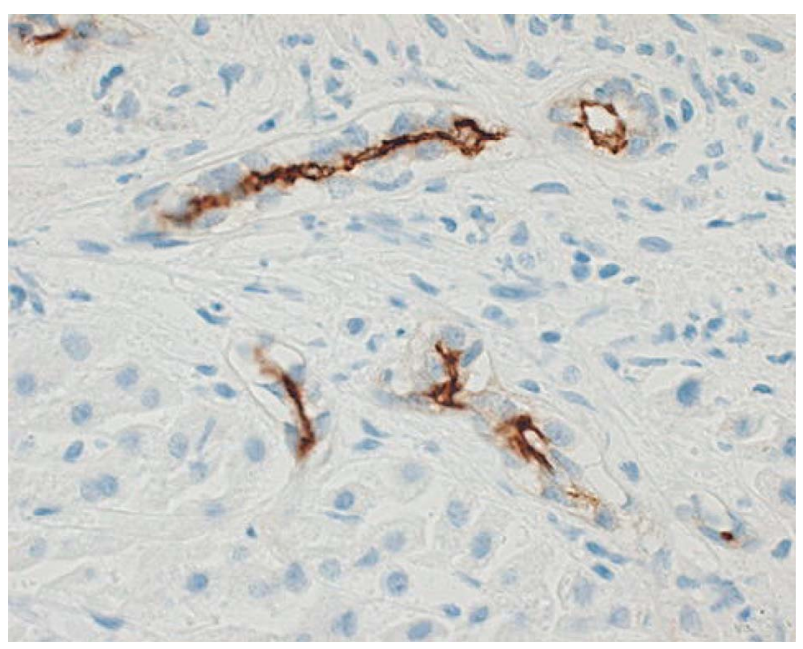

Figure 1. Immunohistochemical analysis. 
Table 2. Immunostaining of brain metastasis.

\begin{tabular}{ccccccc}
\hline \multirow{2}{*}{ Stain } & \multicolumn{2}{c}{$\begin{array}{c}\text { lung cancer met } \\
(\mathrm{n}=10)\end{array}$} & \multicolumn{2}{c}{$\begin{array}{c}\text { breast cancer met } \\
(\mathrm{n}=3)\end{array}$} & \multicolumn{2}{c}{$\begin{array}{c}\text { malig.glioma } \\
(\mathrm{n}=2)\end{array}$} \\
\cline { 2 - 7 } & $(+)$ & $(-)$ & $(+)$ & $(-)$ & $(+)$ & $(-)$ \\
\hline CD133 & $(1 / 10)$ & $(9 / 10)$ & $(0 / 3)$ & $(0 / 3)$ & $(1 / 2)$ & $(1 / 2)$ \\
EGFR & $(6 / 10)$ & $(4 / 10)$ & $(1 / 3)$ & $(2 / 3)$ & $(2 / 2)$ & $(0 / 2)$ \\
MT1-MMP & $(7 / 10)$ & $(2 / 10)$ & $(1 / 3)$ & $(1 / 3)$ & $(1 / 2)$ & $(1 / 2)$ \\
MMP7 & $(1 / 10)$ & $(7 / 10)$ & $(1 / 3)$ & $(1 / 3)$ & $(0 / 2)$ & $(2 / 2)$ \\
CD44 & $(0 / 10)$ & $(10 / 10)$ & $\mathrm{ND}^{\mathrm{b}}$ & $\mathrm{ND}$ & $(0 / 2)$ & $(1 / 2)$ \\
\hline
\end{tabular}

${ }^{\mathrm{a}}$ met; brain metastasis from lung adenocarcinoma, ${ }^{\mathrm{b}} \mathrm{ND}$; not done.

Table 3. Summary of detection of CD133, EGFR, MT1MMP, MMP7, and CD44 mRNA expression in brain tumors by RT-PCR technology.

\begin{tabular}{cccc}
\hline mRNA & $\begin{array}{c}\text { lung cancer met. } \\
\text { positive No.of }^{a} \\
\text { meta }^{\text {evaltotal }}\end{array}$ & $\begin{array}{c}\text { breast cancer met. } \\
\text { positive No.of } \\
\text { meta } / \text { total } \\
\text { evaluated }\end{array}$ & $\begin{array}{c}\text { Malig.glioma } \\
\text { positive No/total } \\
\text { evaluated }\end{array}$ \\
\hline CD133 & $2 / 10(20 \%)$ & $0 / 3(0 \%)$ & $1 / 2(50 \%)$ \\
EGFR & $8 / 10(80 \%)$ & $1 / 3(33 \%)$ & $1 / 2(50 \%)$ \\
MT1-MMP & $7 / 10(70 \%)$ & $1 / 3(33 \%)$ & $1 / 2(50 \%)$ \\
MMP7 & $1 / 10(10 \%)$ & $1 / 3(33 \%) / 5$ & $0 / 2(0 \%)$ \\
CD44 & $0 / 10$ & $\mathrm{ND}^{\mathrm{b}}$ & $0 / 2(0 \%)$ \\
\hline
\end{tabular}

amet; brain metastasis, ${ }^{\mathrm{b}} \mathrm{ND}$; not done. ${ }^{\mathrm{c}}$ meta; brain met. from lung adenocarcinoma, ${ }^{\mathrm{d}}$ met; brain meta. from lung squamous cell cancer.

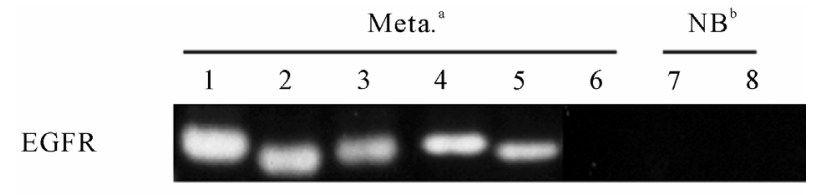

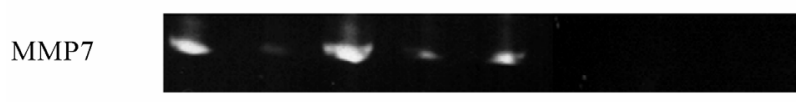

MT1-MMP

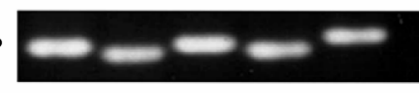

GAPDF

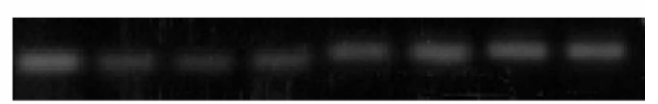

Figure 2. The relative gene expression levels of brain metastasis.

MT1-MMP was relatively correlated with that of EGFR. That is, 63.3\% (19/30) of brain metastasis from lung cancer expressed both EGFR and MT1-MMP mRNA.
However, we could not find any statistical significances in this correlation. No difference in the expression of MMP7 and CD44 was also observed between brain metastasis and normal brain tissue. Furthermore, we could not find any differences of these gene expression in the relationship with the age, sex, and tumor sites (data not shown). There was also no difference in these gene expression between adenocarcinoma and squamous cell carcinoma. Only 4 cases expressed neither detectable levels of EGFR nor MT1-MMP mRNA by RT-PCR. The GAPDH in these cases, however, was detected with similar levels in all cases. These tendency was also observed in brain metastasis from breast cancer. Figure 3 shows the expression of CD133mRNA in patients with lung cancer.

\section{Discussions}

A number of groups have showed that CSCs exist in brain tumors, and CD133 could be a marker of CSCs subpopulation [14]. These CSCs and NOTCH pathway are thought to be important in the proliferation of malignant brain tumors [15].

In the previous study, we have demonstrate that EGFR and MT1-MMP were immunostained predominantly in brain metastasis [13]. The high expression of EGFR and MT1-MMP indicates that an extracellular matrix remodeling may be playing an important role in brain metastasis [16]. In this current study, EGFR immunostaining was detected in $75 \%(6 / 8)$ and $67 \%(1 / 3)$ of brain metastasis from lung adenocarcinoma and breast cancer, respectively. MT1-MMP immunostaining was also detected in $73 \%(8 / 11)$ of these brain metastasis. CD133 was not detected in these 13 patients. Although most cases showed the poor expression of CD133, two patients with malignant brain tumors showed the positive staining of CD133. In these cases, EGFR and MT1-MMP were strongly stained.

Therefore, the potential therapeutic implications of targeting of stem-like cells via NOTCH inhibition extend beyond neuro-oncology, as this signaling pathway has been shown to play a role in CSCs not only in neural tumors, but also in the brain metastasis fro lung and breast cancer [17-19]. More studies will be needed to determine whether pharmacological NOTCH blockade, either alone or in conjunction with other therapies, will be effective in improving the survival of patients with GBM and other malignant tumors.

\section{Conclusions}

The expression of CD133 indicates a marker for brain tumor initiating.

More studies will be needed to determine whether pharmacological NOTCH blockade, either alone or in 

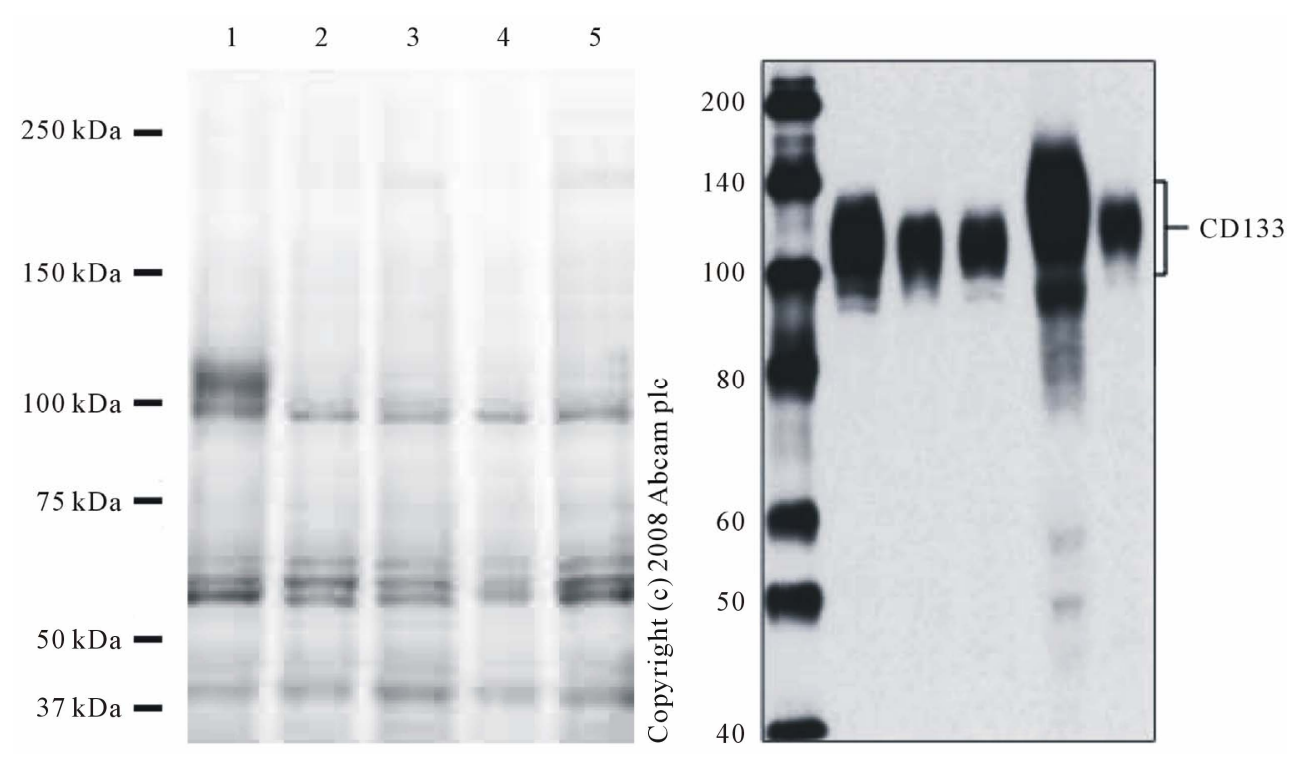

Figure 3. Expression of CD133 mRNA (lung cancer metastasis). Repeated SDS -PAGE analysis of the cerebrospinal fluid and the urine of the 54 years old patients with malignant glioma. Lane 1-2: urinary sample; lane: 3 CSF sample; lane 4: CSF sample at end stage.

conjunction with other therapies, will be effective in improving the survival of patients with GBM and other malignant tumors.

\section{REFERENCES}

[1] T. Reya, S. J. Morrison, M. F. Clarke, et al., "Stem Cells, Cancer, and Cancer Stem Cells," Nature, Vol. 414, No. 6859, 2001, pp. 105-111. doi:10.1038/35102167

[2] H. D. Hemmati, J. Nakano, J. A. Lazareff, et al., "Cancerous Stem Cells Can Arise from Pediatric Brain Tumors," Proceedings of the National Academy of Sciences USA, Vol. 100, 2003, pp. 15178-15183. doi:10.1073/pnas.2036535100

[3] A. M. Bleau, D. Hambardzumyan, T. Ozawa, et al., "PTEN/PI3K/Akt Pathway Regulates the Side Population Phenotype and ABCG2 Activity in Glioma Tumor Stem-Like Cells," Cell Stem Cell, Vol. 4, No. 3, 2009, pp. 226-235. doi:10.1016/j.stem.2009.01.007

[4] M. D. Taylor, H. Poppleton, C. Fuller, et al., "Radial Glia Cells Are Candidate Stem Cells of Ependymoma," Cancer Cell, Vol. 8, No. 4, 2005, pp. 323-335. doi:10.1016/j.ccr.2005.09.001

[5] T. N. Ignatova, V. G. Kukekov, E. D. Laywell, et al., "Human Cortical Glial Tumors Contain Neural Stem-Like Cells Expressing Astroglial and Neuronal Markers in Vitro," Glia, Vol. 39, No. 3, 2002, pp. 193-206. doi:10.1002/glia.10094

[6] X. Fan and C. G. Eberhart, "Medulloblastoma Stem Cells," Journal of Clinical Oncology, Vol. 26, No. 17, 2008, pp. 2821-2827. doi:10.1200/JCO.2007.15.2264

[7] D. Beier, P. Hau, M. Proescholdt, et al., "CD133 (+) and CD133 (-) Glioblastoma-Derived Cancer Stem Cells
Show Differential Growth Characteristics and Molecular Profiles," Cancer Research, Vol. 67, No. 9, 2007, pp. 4010-4015. doi:10.1158/0008-5472.CAN-06-4180

[8] A. T. Ogden, A. E. Waziri, R. A. Lochhead, et al., "Identification of A2B5+ CD133-Tumorinitiating Cells in Adult Human Gliomas," Neurosurgery, Vol. 62, No. 2, 2008, pp. 505-514.

doi:10.1227/01.neu.0000316019.28421.95

[9] G. Liu, X. Yuan, Z. Zeng, et al., "Analysis of Gene Expression and Chemoresistance of $\mathrm{CD}_{133}{ }^{+}$Cancer Stem Cells in Glioblastoma," Molecular Cancer, Vol. 5, 2006, p. 67. doi:10.1186/1476-4598-5-67

[10] B. Sivasankaran, M. Degen, A. Ghaffari, et al., "Tenascin-C Is a Novel RBPJkappa-Induced Target Gene for Notch Signaling in Gliomas," Cancer Research, Vol. 69, 2009, pp. 458-465.

doi:10.1158/0008-5472.CAN-08-2610

[11] X. Fan, I. Mikolaenko, I. Elhassan, et al., "Notch1 and Notch2 Have Opposite Effects on Embryonal Brain Tumor Growth," Cancer Research, Vol. 64, No. 21, 2004, pp. 258-262. doi:10.1158/0008-5472.CAN-04-1446

[12] G. F. Weber and S. Ashkar, "Molecular Mechanisms of Tumor Dissemination in Primary and Metastatic Brain Cancers," Brain Research, Vol. 53, No. 4, 2000, pp. 421-424.

[13] S. Yoshida and H. Takahashi, "Expression of Extracellular Matrix Molecules in Brain Metastasis," Journal of Surgical Oncology, Vol. 100, No. 1, 2009, pp. 65-68. doi: $10.1002 /$ jso. 21296

[14] S. Bao, Q. Wu, R. E. McLendon, et al., "Glioma Stem Cells Promote Radio-Resistance by Preferential Activation of the DNA Damage Response," Nature, Vol. 444, No. 7120, 2006, pp. 756-760. 


\section{doi:10.1038/nature 05236}

[15] L. Dang, X. Fan, A. Chaudhry, et al., "Notch3 Signaling Initiates Choroid Plexus Tumor Formation," Oncogene, Vol. 25, No. 3, 2006, pp. 487-491.

[16] R. H. Goldbrunner, J. J. Bernstein and J. C. Tonn, "Cell-Extracellular Matrix Interaction in Glioma Invasion," Acta Neurochir (Wien), Vol. 141, 1999, pp. 295305. doi:10.1007/s007010050301

[17] Y. Miyamoto, A. Maitra, B. G. Zech, et al., "Notch Mediates TGF Alpha-Induced Changes in Epithelial Differentiation during Pancreatic Tumor Genesis," Cancer Cell, Vol. 3, No. 6, 2003, pp. 565-576.

\section{doi:10.1016/S1535-6108(03)00140-5}

[18] P. O. Charoenrat, P. Rhys-Evans and S. A. Eccles, "Expression of Matrixmetalloproteinases and Their Inhibitors Correlates with Invasion and Metastasis in Squamous Cell Carcinoma of the Head and Neck," Arch Otolaryngol Head Neck Surgery, Vol. 127, 2000, pp. 813-820.

[19] S. G. Piccirillo, B. A. Reynolds, N. Zanetti, et al., "Bone Morphogenetic Proteins Inhibit the Tumorigenic Potential of Human Brain Tumor-Initiating Cells," Nature, Vol. 444, No. 7120, 2006, pp. 761-765.

doi: $10.1038 /$ nature 05349 